\title{
Experimental Researches to Establish the Optimum Hardbanding Technology and Materials of the Heavy Weight Drill Pipe
}

\author{
Mihaela Madalina Caltaru ${ }^{1}$, Razvan George Ripeanu ${ }^{1, *}$, Marius Badicioiu ${ }^{1}$, and Dragos \\ Gabriel Zisopol ${ }^{1}$ \\ ${ }^{1}$ University Petroleum-Gas of Ploiesti, Department of Mechanical Engineering, Blvd. Bucuresti, \\ no.39, 100680, Ploiesti, Romania.
}

\begin{abstract}
The heavy weight drill pipe, one of the most expensive components of the drill string, is exposed, beside fatigue and corrosion, to an intensive wear process as a result of the friction with the inner wall of the casing or the borehole wall, that lead to a drastically decrease of it durability. In order to improve the durability, the worldwide specialists apply the hardbanding technology to increase the heavy weight drill pipe wear resistance. The major problem raised by the hardbanding process is the selection of the most suitable wear resistant alloy and the optimum hardbanding technology. The present research work investigate the possibility of hardbanding the heavy weight drill pipes by using the gas metal arc welding process, taking into considerations three different wear resistant materials with the trade name ARNCO 100XT, ARNCO 300XT and FLUXOFIL M58.
\end{abstract}

\section{Introduction}

In the petroleum industry, the drill string is the drilling assembly that is used to rotate the bit, to conduct the drilling fluid to the bit, to realize the weight on bit and control the drill bit, [1]. Wear, corrosion and fatigue are recognized as a major cause of drill string failures. In practice, the oil industry attempts to guard against the likelihood of these costly failures by improving the surface characteristics of the drill string components, by using different technologies, $[1,2]$.

The heavy weight drill pipes, the most expensive elements of the drill string, are inserted between the drill collars and drill pipes in order to ensure that the drill pipe string is kept in tension and realize a flexible transition between the stiffer drill collars and limber drill pipe, [1]. The heavy weight drill pipe has the same outside diameter as standard drill pipe but a much reduced internal diameter, has an extralong tool joint (pin/box) and an integral centre wear pad (midsection/centre upset) which acts as a stabilizer, increasing the overall stiffness of the drill string (fig.1), $[1,2]$. Due to friction with the inner surface of the casing (that prevent the borehole from caving in and to support the weak or fractured formations) or the open hole wall, the durability of the heavy weight drill pipes decreased,

*Corresponding author: rrapeanu@upg-ploiesti.ro 
and to improve it, the worldwide specialists apply hardbanded wear resistant materials onto the surface subjected to wear, respectively onto the tool joint pin/box of the heavy weight drill pipe and onto the central zone of the pipe (fig. 1), [1, 2].

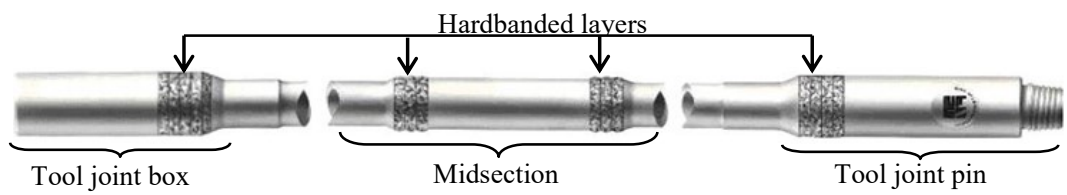

Fig.1. The hardbanding areas of the heavy weight drill pipe.

The deposit hardness is very important in the drilling process because a value higher than 57-62 HRC will cause an excessive wear of the casing, [3, 4, 5]. The present paper bring forward the results obtained in the case of three different wear resistant wires, FLUXOFIL M58, ARNCO 100XT and ARNCO 300XT, used for heavy weighty drill pipes' hardbanding.

\section{Experimental procedures}

\subsection{Materials}

The experimentally researches were performed on specimens manufactured by steel AISI $4145 \mathrm{H}$ (46MoMnCr10), the reference material utilized in heavy weight drill pipes construction. The chemical composition and the mechanical characteristics of the AISI $4145 \mathrm{H}$ steel, according to the manufacturer, are presented in table 1, [3].

Table 1. Chemical characteristics of AISI 4145H alloy steel.

\begin{tabular}{|c|c|c|c|c|c|c|c|c|c|c|c|c|c|}
\hline C, & Mn, & Si, & $\mathbf{P}$ & S, & Cr, & 10, & Al, & $\mathbf{N i}$ & $\mathbf{C u}$, & Hardness & \begin{tabular}{|l|} 
Tensile \\
strength
\end{tabular} & Elon: & ion \\
\hline$\%$ & $\%$ & $\%$ & $\%$ & $\%$ & $\%$ & $\%$ & $\%$ & $\%$ & $\%$ & HB & $\begin{array}{c}\mathbf{R}_{\mathrm{m}} \\
\mathbf{N} / \mathbf{m m}^{2}\end{array}$ & $\mathrm{~A}, \%$ & $\mathrm{Z}, \%$ \\
\hline 43 & 0.97 & 0.3 & & & .99 & 0.21 & لي 028 & 0.11 & 0.14 & 336 & \begin{tabular}{|l|}
1124.7 \\
\end{tabular} & 14.75 & 51. \\
\hline
\end{tabular}

The specimens used had $1500 \mathrm{~mm}$ length, considered to be sufficient to reproduce the heating and cooling conditions of the hardbanded area under real conditions, with different outer diameters, that corresponds to the surfaces subjected to hardbanding, respectively $\phi$ $133.3 \mathrm{~mm}$ (corresponding to the outer diameter of the tool joint pin/box) and $\phi 114.3 \mathrm{~mm}$ (corresponding to the midsection), with an inner diameter of $\phi 63.5 \mathrm{~mm}$. A recess grove was machined onto the specimens (fig. 2) to be filled flush with hardbanding material in order to avoid the wear of casing inner diameter, [3]
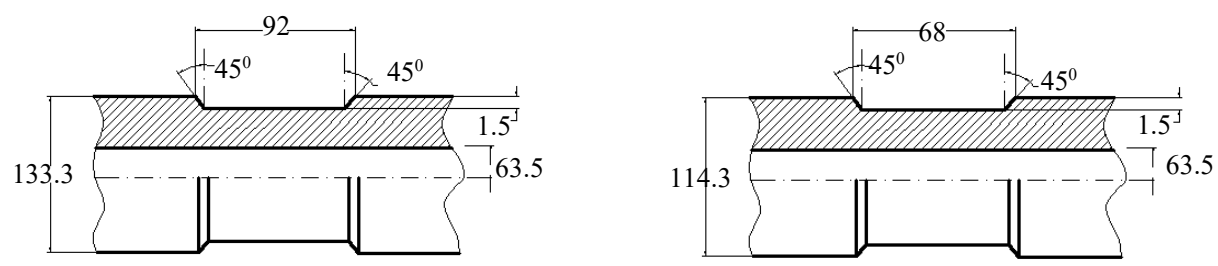

Fig.2. Recess grove of the specimens.

In the experimental works were used tree different wear resistant flux core tubular wires of $1.6 \mathrm{~mm}$ diameter, named FLUXOFIL M58, ARNCO 100XT and ARNCO 300XT, having the characteristics, according to manufacturer, presented in table 2, [3] 
Table 2. The deposit characteristics.

\begin{tabular}{|c|c|c|c|c|c|c|c|c|c|c|c|c|}
\hline \multirow[b]{2}{*}{$\begin{array}{l}\text { Type of } \\
\text { wire }\end{array}$} & \multicolumn{11}{|c|}{ Chemical composition of the deposit } & \multirow{2}{*}{\begin{tabular}{|c} 
Hardness \\
$H R C$
\end{tabular}} \\
\hline & $\begin{array}{l}C, \\
\%\end{array}$ & $\begin{array}{c}M n, \\
\%\end{array}$ & $\begin{array}{l}\mathrm{Si}, \\
\%\end{array}$ & $\begin{array}{l}P, \\
\%\end{array}$ & $\begin{array}{l}S, \\
\%\end{array}$ & $\begin{array}{c}\mathrm{Cr}, \\
\%\end{array}$ & $\begin{array}{c}\text { Mo, } \\
\%\end{array}$ & $\begin{array}{c}\mathrm{Nb}, \\
\%\end{array}$ & $\begin{array}{c}\mathrm{Ni} \\
\%\end{array}$ & $\begin{array}{l}B, \\
\%\end{array}$ & $\begin{array}{l}\mathrm{Fe}, \\
\%\end{array}$ & \\
\hline $\begin{array}{l}\text { ARNCO } \\
100 X T\end{array}$ & \begin{tabular}{|l|}
$0.7-$ \\
0.75 \\
\end{tabular} & $1 \max$ & $\begin{array}{c}0.5-07 \\
\max \end{array}$ & $\begin{array}{c}0.030 \\
\max \end{array}$ & $\begin{array}{c}0.030 \\
\max \end{array}$ & 1.00 .0 & .20 & - & - & - & rest & $48-52$ \\
\hline $\begin{array}{c}\text { ARNCO } \\
300 X T\end{array}$ & $\begin{array}{l}0.75- \\
0.80\end{array}$ & \begin{tabular}{|c|}
$0.90-$ \\
1.2 \\
\end{tabular} & $\begin{array}{c}0.55- \\
0.75 \\
\end{array}$ & $\begin{array}{c}0.030 \\
\max \end{array}$ & $\begin{array}{c}0.030 \\
\max \end{array}$ & - & - & $\begin{array}{l}5.3- \\
5.7 \\
\end{array}$ & $\begin{array}{l}2.0- \\
2.5 \\
\end{array}$ & $\begin{array}{c}3.8- \\
4.2 \\
\end{array}$ & rest & 60 \\
\hline $\begin{array}{c}\text { FLUXOFIL } \\
\text { M58 }\end{array}$ & $\begin{array}{c}0.45- \\
0.85 \\
\end{array}$ & \begin{tabular}{|l|}
$1.5-$ \\
2.1 \\
\end{tabular} & $\begin{array}{l}0.50- \\
0.85 \\
\end{array}$ & 0.020 & 0.020 & $5.0-7.0$ & $0.35-0.85$ & - & - & - & rest & $57-62$ \\
\hline
\end{tabular}

The metal active gas welding process (GMAW) was used for hardbanding.

\subsection{Hardbanding equipment}

The hardbanding equipment, used, allowed, from the cinematic point of view, the following movements: continuous rotation of the specimen, axial feed of the welding torch and oscillate the welding torch (fig. 3), [3, 4].

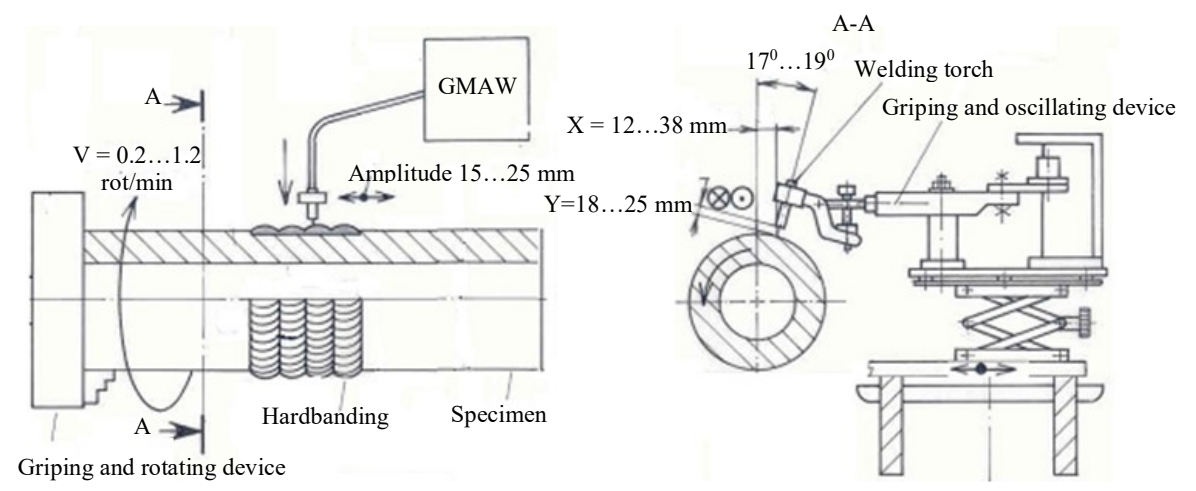

Fig. 3. The hardbanding equipment scheme.

\subsection{Hardbanding research methodology}

In order to establish the optimum hardbanding technology, based on the own experience, on the wear resistant wires manufacturers' recommendations and on the technical information presented in the specialized literature by the specialists, the methodology presented below has been applied, [3].

A) Specimen preparation - After turning the specimen by using a lathe machine, in order to prepare the recess grove, a visual inspection of the specimen's surface was performed, to ensure it is clean and without rust, dirt, grease, oil etc.

B) Preheating the specimen - Before the hardbanding process, the specimen was preheated at 100 degree Celsius, in order to not cause undesirable cracking in the parent metal).

C) Hardbanding the specimen - The number of the hardbanded layers and the order of their applications were different, depending on the width of the hardbanded area (fig. 4). 

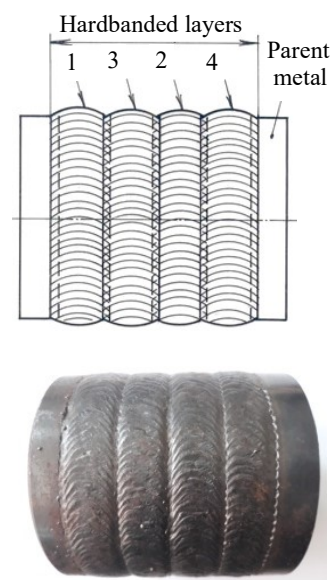

specimens with outer diameter $\phi 133,3 \mathrm{~mm}$
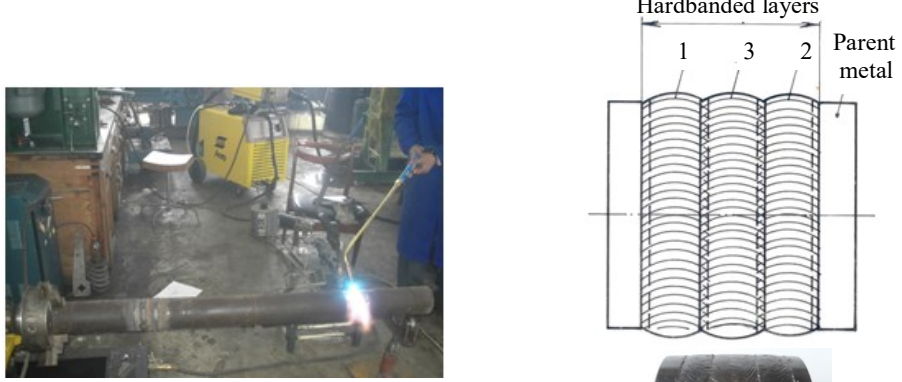

Hardbanded area - sample cut

Picture during hardbanding process

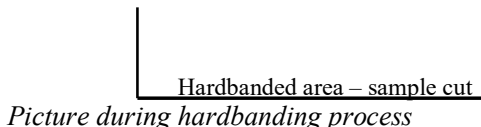

specimens with outer diameter $\phi 114,3 \mathrm{~mm}$

Fig.4. Applications of the hardbanded layers.

The recess grove of the specimen was filled flush with hardbanding material by using the technological parameters mentioned in table 3 .

Table 3. Hardbanding technological parameters.

\begin{tabular}{|c|c|c|c|}
\hline \multirow{2}{*}{ Tachnological parameter } & \multicolumn{3}{|c|}{ Type of wear resistant wire /adopted values } \\
\cline { 2 - 4 } & FLUXOFIL M58 & $\begin{array}{c}A R N C O \\
100 X T\end{array}$ & $\begin{array}{c}A R N C O \\
300 X T\end{array}$ \\
\hline Polarity & reverse & reverse & reverse \\
\hline Amperage $I_{s}, \mathrm{~A}$ & $250 \ldots 270$ & $250 \ldots .270$ & $250 \ldots 270$ \\
\hline Voltage $U_{a}, \mathrm{~V}$ & $23 \ldots 25$ & $23 \ldots .25$ & $23 \ldots 25$ \\
\hline Shielding gas & $80 \% \mathrm{Ar}+20 \% \mathrm{CO}_{2}$ & $100 \% \mathrm{CO}_{2}$ & $100 \% \mathrm{CO}_{2}$ \\
\hline Shielding gas flow rate $Q_{g}, 1 / \mathrm{min}$ & 13.5 & 14 & 14 \\
\hline Filler metal speed $v_{s m}, \mathrm{~m} / \mathrm{min}$ & 4.5 & 4.5 & 4.5 \\
\hline$Y$ distance (from figure 3$), \mathrm{mm}$ & 20 & 20 & 20 \\
\hline$X$ distance (from figure 3$), \mathrm{mm}$ & 20 & 20 & 20 \\
\hline Rotating speed of the specimen, rot/min & & & \\
- for specimens with $\phi 133,3 \mathrm{~mm}$ & 0.57 & 0.57 & 0.57 \\
- - for specimens with $\phi 114,3 \mathrm{~mm}$ & 0.66 & 0.66 & 0.66 \\
\hline Welding speed $v_{s}, \mathrm{~m} / \mathrm{h}$ & 14.5 & 14.5 & 14.5 \\
\hline Oscillating the welding torch: & & & \\
- oscillating speed, oscillation $/ \mathrm{min}$ & 60 & 60 & 60 \\
- oscillation amplitude, mm & 25 & 25 & 25 \\
\hline Preheat temperature $T_{p r},{ }^{0} \mathrm{C}$ & 100 & 100 & 100 \\
\hline Maximum interpass temperature, ${ }^{0} \mathrm{C}$ & 350 & 350 & 350 \\
\hline
\end{tabular}

D) Controlled cooling of the hardbanded specimen - After finishing the hardbanding process, the hardbanded specimens were slowly cooled by using a thermal isolated blanket with a thickness of $100 \mathrm{~mm}$, to avoid the cracks in the hardbanded layers.

E) Quality Control - After cooling of the specimens, the quality of the hardbanded area was verified by: macroscopic analyses, metallographic analyses by optical microscopy, Rockwell hardness and micro hardness measurements.

\subsection{Experimental results and discussion}

The macroscopic analyses consisted in investigation by naked eye of the hardbanded layers had indicated that the profiles of the hardbanded layers are flat (deviation from this kind of 
profile can cause premature wear of the casing, when the profile is convex, or premature wear of the heavy weight drill pipe, when the profile is concave, [4]). The surface of the hardbanded layers with ARNCO 100XT and FLUXOFIL M58 doesn't contain visible cracks, but in the case of ARNCO 300 XT the cracks were observed. The adhesion between the substrate (parent metal) and the hardbanded layers, also between two adjacent layers is good (without any discontinuities or voids).

The metallographic analyses by optical microscopy were performed on metallographic samples cut from the transition zone parent metal-hardbanded layer, also from the overlap zone between two adjacent hardbanded layers. In figure 5 are presented the metallographic structures obtained for the hardbanding. The analysis shows a good adhesion between the hardbanding and the parent metal, and without any cracks for layers hardbanded with ARNCO 100XT and FLUXOFIL M58. In the case of layers hardbanded with ARNCO 300XT, the high percent of niobium leads to the separation of primary niobium carbide, and the high percent of boron leads to the separation of borides, and the separation of these chemical compounds (crystals of carbides and borides) places this material in the field of cast irons. The transition area from the hardbanded layer to the parent metal is more obvious, in this case, which also explain the appearance of cracks (fig. 5).
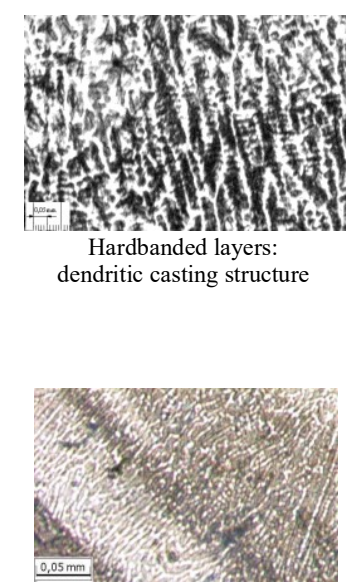

Hardbanded layers: dendritic casting structure with carbides separation

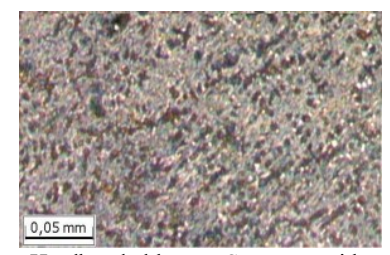

Hardbanded layers: Structure with separation of primary niobium carbides and borides (crystals)
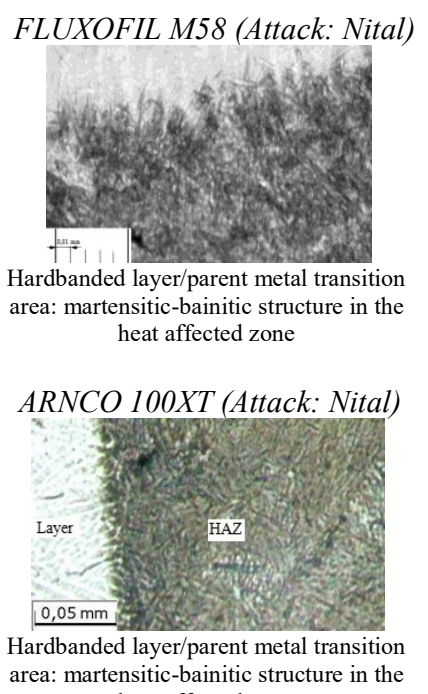
heat affected zone

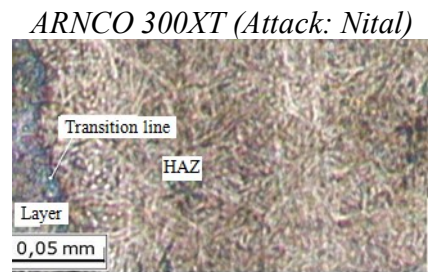

Hardbanded layer/parent metal transition area
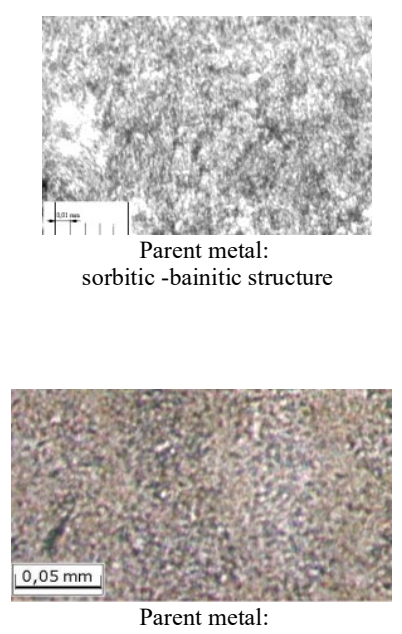

sorbitic -bainitic structure

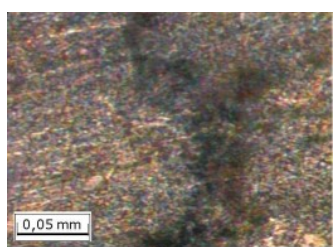

Crack in hardbanded layer

Fig. 5. Metallographic structures for the hardbanding.

The Rockwell hardness measurements were performed on metallographic samples, and the average values of HRC hardness are presented in table 4. 
Table 4. Rockwell hardness measurements.

\begin{tabular}{|l|c|c|c|}
\hline \multirow{2}{*}{ Type of wire } & \multicolumn{3}{|c|}{ Rockwell hardness, [HRC] } \\
\cline { 2 - 4 } & Hardbanded layer & Heat affected zone & Parent metal \\
\hline FLUXOFIL M58 & 55 & 50 & 36 \\
\hline ARNCO $100 X T$ & 58 & 52 & 36 \\
\hline ARNCO $300 X T$ & 62 & 55 & 37 \\
\hline
\end{tabular}

The micro-hardness measurements were performed on metallographic samples with a load of $100 \mathrm{~g}$. The measurements performed shown high values of hardness in the hardbanded layers and a maintaining initial hardness in the parent metal (fig. 6).
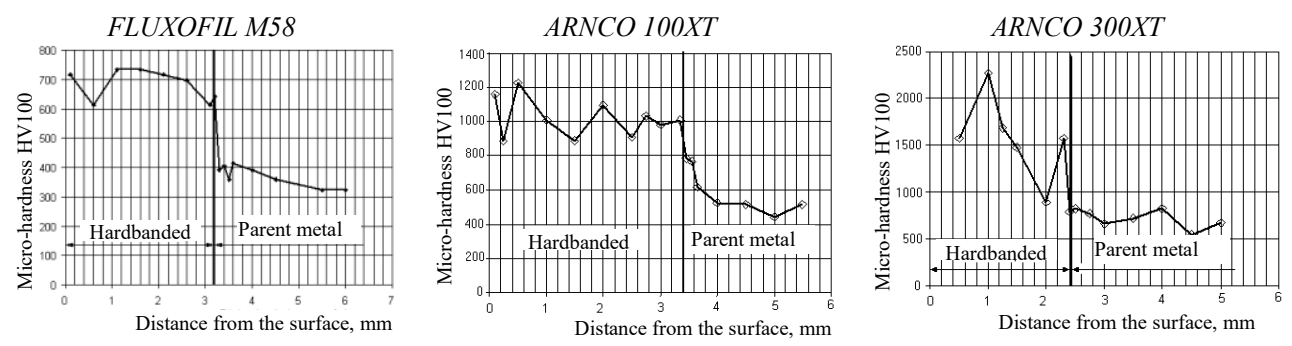

Fig.6. Micro-hardness of the hardbanding.

\section{Conclusions}

The hardbanding equipment and the hardbanding technology developed in the frame of this research work allow to perform, in good conditions, the hardbanding with wear resistant alloys of the heavy weight drill pipes, by using the gas metal arc welding - GMAW process. The comparative researches performed with three different wear resistant materials, have shown that ARNCO 100XT wire, successfully used worldwide for hardbanding of the tool joints and the drill collars, can be replaced with the FLUXOFIL M58 wire, available in our country, allowing the delivery of heavy weigh drill pipes hardbanded, competitive worldwide from the point of view of the quality of the hardbanded layers and, at the same time, at a lower price. The experimental results obtained do not recommend the wire ARNCO 300XT to be use for hardbanding of the heavy weigh drill pipes because the hardbanded layers cracks.

\section{References}

1. V. Ulmanu, Drillpipe \& BHA Design and Components, Well Academy Program, Petrom-OMV, p. 71, (2009).

2. V. Ulmanu, Petroleum Equipment Manufacturing and Repairing Technology (in Romanian), ILEX Publ. House, (2002).

3. V. Ulmanu, M. Minescu, Gh. Zecheru, Gh. Drăghici, D. G. Zisopol, M. Călţaru, M. Bădicioiu, C.N. Trifan, Manufacture the heavy weight drill pipe competitive worldwide by hardbanding with wear resistant alloys (Research project no. 2053/2004 - in Romanian), Petroleum-Gas University, (2006).

4. Arnco Technology Trust Limited, Arnco hardbanding specification for the preparation, application and inspection of Arnco hardbanding products (100XT, 150 $X T, 300 X T$ and 350XT), Version 2.1. June 28th (2012).

5. K. Zhang, Z. Wang and D. Wang, Research Progress of the Drill String Hardbanding Materials, DOI: http://dx.doi.org/10.5772/intechopen.90013, (2019). 